\title{
LA PRAGMÁTICA TEATRAL EN ALFONSO VALLEJO
}

\author{
Francisco GUTIÉRREZ CARBAJO \\ UNED, Madrid
}

La Pragmática ha contribuido, entre otras cosas, a superar la cacareada «crisis de la referencialidad del lenguaje» y a poner coto a las tesis de las posibles derivas infinitas del significado. Algunos de los defensores de la idea peirceana de semiosis ilimitada o del concepto de obra abierta, como Umberto Eco (1962), han reaccionado, introduciendo correcciones en trabajos posteriores, como Los límites de la interpretación (1992) o Interpretación y sobreinterpertación (1995).

El logocentrismo, con las excepciones de Derrida y otros autores, ya no es defendido con ardor, y hoy no parece que existan reparos en proclamar abiertamente una gramática de la significación y en buscar el sentido del texto más allá de las fronteras de lo puramente verbal.

No queremos entrar aquí en la concepción amplia de texto defendida por la Escuela de Tartu y por ciertos seguidores de Bajtín, pero sí proponer que cualquier texto -y el texto teatral quizá más que ninguno otro- no se agota en los límites de sus elementos verbales. El mapa de lo textual es mucho más amplio, y en él, junto al componente verbal -y acompañándolo y enriqueciéndolo- podemos señalar una serie de elementos, algunos de ellos ya apuntados por la filosofia del lenguaje y por la teoría de los actos de habla. En este sentido, hemos subrayado, por ejemplo, la función de la didascalia, como marcas de las condiciones de ejercicios de habla de los personajes de Vallejo (Gutiérrez Carbajo, 2001 b: 173 y ss.), y ahora nos parece oportuno ampliar ese mapa, con la explicación de las circunstancias que precedieron al texto teatral o con las que limitan o traspasan sus fronteras.

El texto teatral puede ser considerado un hipotexto respecto a lo que denominamos texto marco o texto matriz. Este texto marco. según nuestra hipótesis 
abductiva, estaría constituido por todo el contexto espaciotemporal en el que se inscriben tanto el texto escrito (texto auctorial, didascalia, paratexto...), como el texto espectacular o representación dramática. La pragmática teatral concede un papel relevante a las estrategias indirectas del autor-enunciador y al trabajo de interpretación de los textos por parte del receptor-espectador. Es decir, el sistema lingüístico constituido por el discurso auctorial y por el de los personajes, con sus funciones sintácticas y sus valores semánticos, reclama un marco pragmático para constituir el hecho teatral como sistema general (Gutiérrez Carbajo, 2001b: 161). Este sistema se actualiza en la representación gracias a los actores y al director de escena, decoradores y tramoyistas, y ha de completarse con las diversas presuposiciones e inferencias abductivas del público espectador. Con mayor exigencia que cualquier otro texto, el discurso teatral textual y el discurso teatral espectacular han de ser completados por el receptor-espectador, que, a través de su proceso de interpretación, construye, como diría Umberto Eco (1995: 17), mundos actuales y posibles.

Al hablar del discurso teatral conviene evitar el peligro del mencionado «logocentrismo», que sobrevalora las palabras en detrimento de los códigos no verbales así como los presupuestos que invierten axiológicamente los términos de esta dialéctica, tal como aparecen expuestos en el conocido libro de Antonin Artaud El actor y su doble.

En esta concepción de la pragmática se enmarcan también las «circunstancias dadas» a las que se refiere Stanislavski (1953) y las que define Pavis (1996: 198) como «situaciones de enunciación». Si, según Ducrot (1984: 43-44), la mayoría de nuestras manifestaciones lingüísticas constituye las partes integrantes de un discurso más amplio, el discurso teatral apela continuamente a las circunstancias anteriores a la puesta en escena, a las condiciones y situaciones de interpretación de los actores y al amplio horizonte de expectativas del receptor. Este último aspecto, que es predicable de cualquier texto, en el texto teatral espectacular alcanza una especial dimensión, ya que parte de esas expectativas se concretan -se confirman o se frustran- en la interacción directa entre el actor y el espectador.

Estas consideraciones teóricas, tal vez de utilidad para acercarnos a la trayectoria teatral de todo autor, resultan casi necesarias para contextualizar la obra dramática de Alfonso Vallejo, sobre cuya ubicación -como ya hemos expuesto en otros lugares (Gutiérrez Carbajo, 2001b: 11-13 y 2003: 95-96)-, no hay acuerdo entre los estudiosos. Así, Enrique Llovet subraya «su aislamiento de la tensión diaria de las camarillas, rigurosamente contrapesado con una firme atención a cualquier indicación crítica» (Vallejo, 1980: 12), y José Monleón no duda en proclamar que «nuestro Alfonso Vallejo no se ha visto beneficiado por ninguna coyuntura» (Vallejo, 1978: 11). 
Fernández Santos, por su parte, resalta su condición de «autor-isla, cuya pasión por la escena es tan nítida, que parece haber encontrado su camino natural fuera de los circuitos habituales del negocio del teatro en España» (Vallejo, 1985 b: 8). En la misma línea se ha valorado su carácter de dramaturgo independiente y superador del realismo, «aunque varias de sus obras se asemejen a algunas de las rupturas que, desde esa misma estética, hicieron en los años setenta otros autores» (Oliva, 1989: 450). Esa actitud de independencia artística y política ha sido subrayada por otros investigadores (Centeno, 1996: 233; Coco, 2000: 231) y por la crítica en general, que no dudó en considerarlo un «escritor de vanguardia», a raíz del estreno de sus primeras obras. El propio Alfonso Vallejo se ha definido a sí mismo como «un escritor solitario e independiente», no vinculado «a ningún grupo artístico o literario» (Santa Cruz, 1984: 26).

Otros historiadores lo inscriben en la «generación de la transición» (Gómez García, 1996: 236) o lo sitúan, junto con Francisco Nieva y Ángel García Pintado, en la tendencia «renovadora-rupturista» (Berenguer y Pérez, 1998).

Al igual que Fernández Santos, María José Ragué-Arias (1996: 193-194) lo califica de «autor isla», mientras que Úrsula Aszyk (1995: 200) sitúa su teatro «al borde de la posvanguardia y la posmodernidad», $y$, en un sentido análogo, es incluido, junto con Eduardo Quiles, «entre los autores apegados a la estética vanguardista» (Pedraza Jiménez y Rodríguez Cáceres, 1997).

Al estudiar la dramaturgia española de los ochenta y noventa del siglo XX, Wilfried Floeck se refiere a la singularidad del teatro de Vallejo y a su distanciamiento de la actividad teatral madrileña dominante por su condición de médico en ejercicio (Toro-Floeck, 1995: 37).

Para María Francisca Vilches de Frutos, «los textos de Alfonso Vallejo rezuman contemporaneidad. Sus temas pueden presentarse como paradigmas de las preocupaciones del ser humano en la actualidad. Es un autor que arranca a la vida los materiales de su discurso estético, como lo atestigua la fuerza desgarradora del leitmotiv que surca una y otra vez sus creaciones: las relaciones de poder en el seno de la sociedad, concretadas en el progresivo aniquilamiento de la independencia y libertad del individuo a través de sus principales estructuras, ya sea la familia, los regímenes políticos, el sistema sanitario, el ejército, el mundo artístico, las relaciones de vecindad o la amistad» (Vilches de Frutos, 1999: 7-8).

Ignacio Amestoy (1993: 17) percibe en algunas obras de Vallejo «el perfume del underground, pero ya con unas peculiaridades que van a conformar una punta de posmodernidad». En el contexto de la generación «underground», analizada por Wellwarth (1978), Amestoy advierte que, si no supiéramos que Vallejo es español, podríamos perfectamente encuadrar su dramaturgia «en los meridianos de la geografia teatral de los O'Neill, Williams, Miller o Albee». 
Dentro del panorama del teatro español del último tercio del siglo XX, Alfonso Vallejo, junto con Sanchis Sinisterra, Alonso de Santos, Fermín Cabal, Romero Esteo, Luis Riaza, López Mozo, Ignacio Amestoy, Sebastián Junyent, y otros dramaturgos, viene siendo incluido en el denominado «nuevo teatro», cuyos autores más representativos se dan a conocer durante el período de la transición española, aunque la mayoría había escrito ya en tiempos de la dictadura (Oliva, 1989 y 1992). No resulta infrecuente encontrar alineados con los anteriores a dramaturgos cultivadores de un teatro experimental y vanguardista como Fernando Arrabal y Francisco Nieva. En relación con buena parte de los autores citados se ha hablado también de «la generación más premiada y menos representada» (Miralles, 1977).

Volviendo a la pragmática teatral, lo que llamamos elementos del subtexto o pretexto teatral están en la periferia del discurso teatral, incluso del discurso teatral espectacular, pero resultan muy importantes para conocer el fenómeno dramático en su totalidad. Si hubiésemos tenido la ocasión de dialogar con Shakespeare o con Lope, nos habrian iluminado muchas cuestiones que desgraciadamente hoy están en la sombra. En la imposibilidad de una conversación real con los dramaturgos citados, la hemos mantenido con Alfonso Vallejo, y lo que sigue son algunas de sus observaciones. Constituyen testimonios de su pragmática teatral. Bordeamos, por tanto, el texto, estamos en la periferia del mismo, y en algunos casos nos adentramos en algunas de sus capas.

EI recorrido que realizamos no sigue necesariamente una cronología lineal. Así, Fly-By (1973), estrenada en Orange Tree de Londres en 1979 -y definida en el mundo anglosajón como una alegoría-implica un subtexto implícito ya en la propia elección del título, que inicialmente era Vuelo Magia. Determinada por las circunstancias coercitivas de la Dictadura, el autor se propuso, mediante una metáfora, realizar un canto a la libertad. La obra, como ha explicado Víctor García Catena, sufrió los trámites de la censura, que realizó algunos cortes pero que, afortunadamente, no supo ver su sentido político, lo que hubiese supuesto una mutilación mayor o incluso su prohibición. En la pragmática de la obra destacan experiencias vividas por el autor, entre ellas la impresión proporcionada por las dos primeras autopsias que vio en Medicina Legal en el año 1960. La autopsia de un individuo, que llegó a casa «con unas copas de más» y se prendió fuego, y la de un portero que se subió al séptimo piso de un edificio y se precipitó al vacío. Un cadáver quemado y otro politraumatizado constituyen, por tanto, elementos implícitos del texto teatral, unido al ambiente burocrático de los Ministerios. El individuo quemado está también en la génesis de una obra no conocida de Vallejo, titulada El Bernardo, para cuya construcción el autor visitó la patria de Bernardo del Carpio. Fly-By es una de las piezas más conseguidas de Vallejo; hasta el punto 
que ha intentado una reelaboración de la misma y no la ha rematado: la reescritura seguía por los mismos cauces que la primera.

Acido sulfúrico, accésit del Lope de Vega, se estrenó en el Teatro Martín de Madrid en 1981. Según nos ha confesado el propio autor, entre los antecedentes de Ácido sulfúrico puede citarse una película de vaqueros, que vio en el Cine Europa de Madrid. El protagonista de esta cinta, Zuckerman -el hombre de azúcar, en alemán- se convirtió en uno de los personajes de su comedia. En el macrotexto está también implícito un hecho real, el de un individuo que, con un rifle, realizó una matanza en los Estados Unidos de América. La guerra es otro de los telones de fondo sobre los que se iría proyectando el texto teatral. Por otra parte, de la crónica de sucesos - generadora de abundantes conflictos dramáticos en la obra dramática de Vallejo, y en el teatro en general- extrae el caso del hombre impotente, mutilado por la guerra. La imagen del martillo neumático se la ha proporcionado la escena repetida mil veces en Madrid del obrero que trabaja abrazado a ese instrumento. Esta práctica es responsable de un tipo de enfermedades, con repercusiones en el escafoides y en otros huesos, que el autor, como neurólogo clínico, ha tratado. Fruto de todo ello es un personaje potentísimo en escena, impulsado por la sed de venganza.

El cero transparente, representada en el Orange Tree de Londres en 1979, en el Círculo de Bellas Artes de Madrid en 1980, y merecedora del Premio Fastenrath de la Real Academia Española en 1981, surgió de varios acontecimientos: $1 .^{\circ}$ ) de un viaje a París realizado en el tren Puerta del Sol; $2 .^{\circ}$ ) de la contemplación de una modelo en una revista francesa, que le sirve como motivo para la creación del personaje Carol; $3^{\circ}$ ) del mundo mitológico, y en concreto del personaje de Melampo, que es el que comprendía el canto de los pájaros; $4 .^{\circ}$ ) del controvertido asunto de la eutanasia, que suscitaba y sigue suscitando encendidas polémicas; 5..$\left.^{\circ}\right)$ del mundo de la neurología, algunos de cuyos representantes más ilustres aparecen en la obra con sus propios nombres: Holmes, Foster, Babinski, etc.

El nombre Kiu, con el que se designa el hipotético paraíso al que los locos creen ser conducidos, se lo sugirió al dramaturgo la lectura de un tratado de medicina sobre la esclerosis lateral amiotrófica, una enfermedad rara, que había sido estudiada en las islas Kii del Japón. Al autor le gustó la sonoridad casi onomatopéyica del término y por un efecto de disimilación lo convirtió en Kiu. El bastón con el puñal dentro, con el que Simón mata a Babinski, tiene su correspondencia con el bastón -también con un puñal en su interior- que Alfonso Vallejo le compró a un gitano por tres mil pesetas en la plaza de Santa Ana de Madrid. De la atinada combinación del ritmo del tren, del mundo de la neurología y del de los tipos pintorescos del universo madrileño, puede surgir una obra con vocación de universalidad, como es el caso. 
Con el nombre Kiu montaría Luis de Pablo una ópera en el Teatro de la Zarzuela de Madrid en 1983, basada en El cero transparente. En esta adaptación de la obra teatral desempeñó una importante función el también escritor y neurólogo clínico Alberto Portera, con el que trabajaba Alfonso Vallejo en el Hospital 12 de octubre de Madrid.

El desguace mereció el Premio Lope de Vega en 1977 y fue estrenada en Manzanares en 1980. Es una de las obras con inspiración más explícita en la política internacional del siglo XX, y en concreto, en la ejercida por el imperialismo americano. En El desguace aparecen referencias a personajes de la política norteamericana como Kissinger, y a las circunstancias que desencadenaron la caída del presidente Nixon, como la guerra de Vietnam y el impeachment. También se mencionan publicaciones que desempeñaron un papel decisivo en la suerte del presidente, como el Washington Post. Pero, como no se trata de la obra de inspiración histórica con intención laudatoria, sino de una comedia con un claro propósito crítico, las hipérboles y las glorificaciones ceden el puesto a los recursos paródicos y caricaturescos. El resultado ha sido una espléndida farsa grotesca.

A tumba abierta consiguió el Premio Tirso de Molina en el año 1978 y fue estrenada ese mismo año en el Círculo de Bellas Artes de Madrid. El título y la génesis de la trama se lo sugirió a Vallejo el banderillero Curro de la Riva. Éste, un día en un bar, le relató cómo el también banderillero Paco Pita lo animaba a organizar una fiesta con esta expresión, que tiene más que ver con el mundo del ciclismo que con el del toreo: «Qué, Curro, hoy..., ; a tumba abierta!».

La espalda del círculo (1978), aparte de mediaciones políticas, sociales y culturales, está motivada fundamentalmente por el reto de redefinición de una situación dramática. El autor quería mostrar en escena una pasión imposible, una pasión criminal, entre una espía judía y un ex-nazi alemán; la obra nace, así, del intento de poner a prueba conocimientos dramáticos con unos ingredientes muy determinados. Parte de la premisa de construir una relación al modo de Encadenados, de Alfred Hitchcock.

Eclipse se estrenó en el Open Space Theatre de Nueva York en 1979. Eclipse, al igual que Infratonos, está motivada por la experiencia clínica, la experiencia del diagnóstico y del tratamiento de una enfermedad grave, la leucemia. Es una terrible enfermedad que no se detecta por ningún bulto ni síntoma externo aparente; una enfermedad, que, sin avisar, produce de pronto un debilitamiento general, y que, casi como por un proceso de vampirización, aniquila al sujeto. Esta experiencia clínica de sombra y oscuridad puede convertirse escénicamente en una experiencia salvadora, en una ostensión de luz y de vida. A esta situación, como en Infratonos, se le añaden los conocimientos de filosofía y de mitología que tiene el escritor y el aprovechamiento dramático de las danzas macabras medievales. El mundo mítico subyace en las dos obras, aunque están confeccionadas de manera 
muy distinta: una aparece construida con una dramaturgia muy medida, y la otra presenta una estructura más abierta. En el subtexto de Eclipse, como ya apuntó Layton, late el mito de Alcestes, la historia del que da la vida para salvar a otro.

En la pragmática de Monólogos para seis voces sin sonido, estrenada en 1982 en el St. Clement's Theatre de Nueva York, desempeña una función capital un libro de psiquiatría de Vallejo-Nágera. En él se expone un caso clínico de paranoia de celos: un individuo cree que los pasos del vecino sobre el techo de su piso constituyen mensajes en clave para ponerse en relación con su mujer. Cuando Kunningham baja a escena, comprobamos que se trata de un ser deplorable, con «genitales de astrónomo pobre, raído, sin colores», pero la fuerza dramática y real de los donjuanes competidores es inexplicable: en Los cuernos de don Friolera, doña Loreta le es infiel al teniente de Carabineros don Pascual Astete con Pachequín, «cuarentón cojo y narigudo», barbero de profesión y tocador de guitarra. En Monólogos para seis voces sin sonido, Karl dispara a Kunningham, pero éste no muere, porque en el fondo se trata de una alucinación.

En el origen de una obra encontramos a veces la presencia de otra obra o de una manifestación plástica. La personalidad del poeta romántico Friedrich Hölderlin (1770-1843) se presta mucho a este fenómeno de intertextualidades y transducciones, y así sucede en efecto con los que podríamos llamar los prolegómenos extraescénicos del drama Hölderlin (1981) de Alfonso Vallejo. El autor ha confesado que le sirvió de inspiración la fotografía de la torre de Tübingen en la que permaneció Friedrich Hölderlin desde 1806 a 1843, en una locura atravesada por la poesía, con un viejo piano desafinado, que bien podría ser el símbolo de su estado espiritual. Ello le llevó a Vallejo a leer la obra de Hölderlin y a conocer su trayectoria, que le pareció dramática, y a la lectura de la obra de Nietzsche. De todo ello se nutriría el drama Hölderlin. En la obra dramática, el amor de Hölderlin por Diótima se reproduce escénicamente en la pareja integrada por un sucesor del escritor y por una sucesora de Suzette Borkenstein. La genética no es ajena a esta pasión amorosa.

Orquídeas y panteras se estrenó el día 25 de mayo de 1984 en el Teatro Español de Madrid. Dramáticamente constituye un desafío, semejante al de Sol ulcerado. Cuando en sus talleres el dramaturgo va construyendo Orquideas y panteras, se está planteando el reto de elaborar un melodrama, una tragedia melodramática atravesada por un realismo de tipo psicológico. La inspiración, como en otras obras, se la proporcionó una imagen plástica. En este caso se trataba de la ilustración en una revista italiana de un edificio en construcción, que le impedía a un vecino ver el mar. El vecino entabla un recurso y gana el pleito para que sea volado el edificio. Ello le dio la ocasión de reproducir dramáticamente un espacio en el que situar a Berto Leone y a sus hijas Tina y Julia. En el subtexto de Orquideas y panteras late la historia del drama de Shakespeare El rey Lear y 
sus hijas. En la obra de Vallejo, la influencia italiana - a la que he aludido- está representada por la mafia.

Sol ulcerado (1983) fue estrenada en el teatro Alfil de Madrid en 1993 y tiene, entre otros motivos de su génesis, el mito de Edipo. El autor lo reproduce dramáticamente en las relaciones que se establecen y se cruzan entre el individuo maduro que se casa con una mujer joven, actriz y de una gran belleza, y el hijo del anterior matrimonio. Este último, como en el mito clásico, se enamora de su madrastra.

La obra Monkeys (1985), como otras creaciones vallejianas, está motivada por un reto dramático: el deseo de plasmar en las tablas la angustia metafísica existencial de unos «monos inquietos», perdidos en una nueva situación. La obra surge a partir de una experiencia personal y filosófica real.

El intento de redefinición escénica de una relación de pareja está en el origen de Week-end (1985), según confesión del propio autor. Se trata del matrimonio que se devora, que se divide, que se mata por la simple cotidianidad. El autor parte de la hipótesis de unos Romeo y Julieta de nuestros días sometidos y ahogados por las leyes de la mera convivencia.

En Espacio interior (1986), el drama parte de otra experiencia personal: del sentido de fracaso, de frustración, de agotamiento físico y psicológico.

Un nuevo caso clínico, tratado por el Dr. Vallejo, daría lugar a Cangrejos de pared, estrenada en el Teatro Calderón de Valladolid en 1987. Nos encontramos ahora con una persona que sufre una Corea de Huntington, una enfermedad hereditaria, autosómica, dominante. De este caso clínico extrajo la historia de las dos familias que aparecen en la obra. El nombre de la familia Hellman, en la que sobresale la rubia Olivia Hellman, dotada de elegancia y distinción y con un aire ausente y marfileño, está tomado -según me informa el propio autor- de la dramaturga Lillian Hellman (1905-1984), de la que sería pareja el novelista Dashiell Hammet (1894-1961). El propio nombre nos sugiere que va a provocar algo trágico, ya que Hell significa 'infierno' en inglés. Por otra parte, el cambio de parejas al que se asiste en Cangrejos de pared está influido por la obra ¿Quién teme a Virginia Woolf? (Who's afraid of Virginia Woolf, 1962), del dramaturgo estadounidense Edward Albee.

Un hecho real motivó la creación de Gaviotas subterráneas, que se estrenó en la Sala Olimpia de Madrid en 1987, y ha sido representada, entre otros lugares, en Nuremberg en 1989. Se trata de un nuevo caso tomado de la crónica policíaca: el de un individuo que simula el accidente del coche que ha caído por un acantilado en Alicante, e intenta cobrar el seguro de vida a través de la mujer. El dramaturgo trasladó el asunto al universo escénico, y con el telón de fondo de la crónica negra, construyó una obra sobre la amistad que une a dos hombres desde la etapa de la infancia. 
El fenómeno de la simulación generó igualmente la intriga de Kora (1998). Muestra la situación de un enfermo parapléjico -atendido en el hospital-, que simulaba la enfermedad. El enfermo salió andando del hospital. A este hecho se le sumó otro de la crónica rosa, que trasmitió la televisión: el de un individuo que, a través de la línea erótica, se enamora de una mujer. Unidos estos elementos con otros ingredientes, como el de la exploración neurológica del pene y la cola de caballo (las raíces nerviosas, lumbares y sacras) -explicada en las clases de medicina-, dieron lugar al entramado de la obra.

En el intramundo de Tuatú (1996) subyacen algunos de los elementos utilizados en Gaviotas subterráneas, como el enfrentamiento de dos hombres por una mujer, que escénicamente llega convertirse en un combate de boxeo. En el subsuelo de esta obra laten los misteriosos mecanismos de la mente, tan bien conocidos por el autor.

De algunos de los infiernos de la historia reciente se alimenta Crujidos (1996). Se trata, en concreto, de las prácticas crueles de la dictadura argentina de Videla y de otros generales, que utilizaban, entre sus métodos de extermino, el de arrojar a personas desde los aviones de la muerte. La obra se erige así en un proceso contra estas prácticas execrables. En Crujidos la madre de una de las chicas liquidadas por estos métodos asesinos quiere ajustar las cuentas a uno de estos criminales, que se ha refugiado en Cádiz. La mujer vengadora, para hacer confesar al presunto culpable, empleará algunas de estas prácticas de los represores, como la de la bañera. En este clima trágico se utilizan como procedimientos distanciadores el ambiente carnavalesco de las chirigotas gaditanas y otros recursos como la respuesta que da la mujer cuando le preguntan por su profesión: la vengadora confiesa que es lectora del Centro Dramático Nacional. Por otra parte, los nombres de Carateta y Farfolla corresponden a apodos reales de personajes que ejercen su profesión en el Rastro madrileño y en los ambientes taurinos de la ciudad.

La historia -en este caso la historia antigua- está latente en el texto teatral de Ébola-Nerón (1999), que se estrenó en el Teatro Principal de Alicante en el año 2001. Aquí se une al elemento histórico un cúmulo de experiencias personales. Los datos, historiados entre otros por Pierre Grimald, son reconstruidos en escena. Alfonso Vallejo sostiene la tesis -lo que él llama evidencia- de que Shakespeare es Shakespeare cuando se ajusta a la Historia, o cuando se apega a leyendas, aunque fueran inventadas. Algo similar, según Vallejo, sucede con Lope de Vega. En la historia de Nerón, la trayectoria del Emperador del mundo es de tal inmoralidad, de tal desprecio por las reglas morales, que estaba exigiendo una reconstrucción dramática. El personaje no es sólo irreligioso o inhumano; es sencillamente un animal, un lobo.

Como en otras obras, el mundo del flamenco está presente en la intrahistoria de Jindama, de la que se realizó una lectura dramatizada en la SGAE, dirigida 
por Jesús Cracio. La obra está sacada de la historia real de Cicerón, en la que se detalla la vida de sus asesinos y la de su propia muerte. Todo empieza por Marco Antonio - presentado por el autor como un atleta, como un bello- al que acusa Cicerón de visitar a altas horas de la noche la casa de un latino, una sus muchas debilidades. En la historia teatral, que es la representación de una representación, el papel principal está encarnado en un flamenco fracasado, que pone una agencia llamada Estafasa, para realizar las Declaraciones de Hacienda. Este personaje fracasado lo toma el autor del flamenco «El Niño de los Rincones».

En la periferia e incluso en el centro de Panic (2001) está de nuevo presente la experiencia clínica: la de los casos que atiende diariamente en el hospital y la de las clases que imparte sobre problemas relacionados con la conciencia. Los casos de conciencia son llevados escénicamente a situaciones límite: alucinosis, delirios. Todo ello insertado y unido con el de un herido grave en el atentado de las Torres Gemelas de Nueva York, que ingresa en la UVI y termina muriendo. En ello está implicada -en la realidad y en la obra- la lacra del terrorismo global. Este hecho trágico se cruza con otro de la crónica dramática, el de la fuga fracasada de unos presos de una cárcel parisina. Además, a todos estos componentes se suma el de la suplantación, el del actor que suplanta al personaje.

Hiroshima-Sevilla. 6 A (2003) nace de la intención de hacer un manifiesto contra la era nuclear, contra la posibilidad real de que el mundo se destruya. En la memoria del dramaturgo está la figura del padre de la bomba atómica, Robert Julius Oppenheimer, y en Hiroshima-Sevilla. $6 \mathrm{~A}$, el autor piensa vengarse en cierto modo del personaje histórico, sacando a escena a un descendiente suyo al que llama Tony Oppenheimer, y al que convierte en un pacifista nato, en una especie de Gandhi. Frente a Hiroshima, como centro de la muerte, construye Sevilla, el centro de la luz. En Hiroshima-Sevilla. $6 \mathrm{~A}$, algunos personajes están tomados del mundo o del submundo taurino, como el reventa Miguel Torres «El Gato».

¿Culpable? (en prensa) está basada en una matanza con escopetas realizada por dos escolares en los Estados Unidos de América. Este hecho, por desgracia no infrecuente, trascendió a los diversos medios de comunicación, y Alfonso Vallejo se impuso el reto de escribir esta obra como una respuesta a la violencia.

La experiencia del espectáculo Katacumbia, estrenada en la Sala Tribueñe de Madrid, en mayo de 2004, ha demostrado que es posible realizar un collage teatral con fragmentos de obras anteriores, en el que los distintos textos no se solapen unos a otros sino que se enriquezcan en sus diversas combinaciones. No se trata de elementos yuxtapuestos sino de piezas perfectamente trabadas y organizadas, en una experiencia insólita. Su director y protagonista, José Pedro Carrión, realizó una interpretación espléndida, y se convirtió en el principal hilo conductor de los distintos experimentos. José Pedro Carrión es el paradigma del actor nato, de múltiples registros. 
Si a lo largo de este trabajo nos hemos referido fundamentalmente al pre-texto teatral, en el caso de Katacumbia asistimos a la reelaboración y redefinición del post-texto. Este último texto es el resultado de la combinación de fragmentos de las siguientes obras: Espacio interior, Ácido sulfúrico, A tumba abierta, Orquideas y panteras, Panic y Eclipse.

Como ya observamos en otro lugar (Gutiérrez Carbajo, 2001b), los títulos constituyen elementos muy significativos en el paratexto teatral. Los de Alfonso Vallejo son siempre muy afortunados, y para llegar al definitivo -el que irá estampado al frente de la obra- el autor escribe primero en un folio treinta posibles títulos para la pieza en cuestión. Luego elige el que le parece más acertado. Esta práctica se la sugirió el catedrático de Fisiología de la Universidad Autónoma de Madrid y Decano, el Dr. Salvador Lluch. Se trataba del procedimiento que él utilizaba para los títulos de sus libros y de sus trabajos de investigación. Todos estos títulos han de tener relación con la semántica de la obra, y en muchos casos, el título definitivo es el resultado de una combinación de varios.

Las acotaciones, por su parte, no son en la obra de Vallejo instrucciones para el director de escena, sino que, según el propio autor, desempeñan un papel muy importante en el texto teatral. Se trata, más bien, de pistas o de indicaciones al lector para orientarle sobre cómo el autor ve el texto. Según su propia confesión, son indicaciones espirituales, simbólicas. El trabajo del director y del actor es considerado por Vallejo como el trabajo de creación pura; el que no sea creador no le interesa. El autor compara estas acotaciones con la guitarra en el cante flamenco: la guitarra sirve para acompañar, para apoyar, para enriquecer el cante, no para frenarlo.

En cuanto a que los personajes de sus obras sean designados con frecuencia con nombres extranjeros responde a su idea de que todos somos el mismo hombre. Por otra parte, el hecho de apoyarse en antropónimos no cercanos confiere a sus dramas un carácter mítico y una buscada universalidad.

En el montaje de todos sus textos teatrales, Alfonso Vallejo ha llevado a cabo un seguimiento muy directo, conjuntamente con el director y con los actores. Con frecuencia ha confesado su admiración por el oficio del actor. El prestarse a incorporar los fantasmas y los delirios a su cuerpo, y a sus gestos, supone, entre otras cosas, una entrega al autor. Es un acto de una generosidad tremenda. El actor, en su trabajo, incorpora no sólo el texto del autor sino toda su experiencia personal y social, la propia persona en su totalidad.

Sobre la situación del teatro en general, Alfonso Vallejo confiesa que, en este erial que es hoy la escena española, el hecho de que crezca una florecita ya es suficiente. El autor confiesa, además, que cuando empezó su carrera en el teatro sabía que se enfrentaba a una larga enfermedad. Una enfermedad crónica y de muy mal pronóstico. Ojalá todas las enfermedades se resolvieran en soluciones tan saludables como los textos de sus obras. 


\section{BIBLIOGRAFÍA}

Álvaro, Francisco, El espectador y la crítica. El teatro en España en 1975, Madrid, Prensa Española, 1976.

- «El cero transparente de Alfonso Vallejo», en El espectador y la crítica. El teatro en España en 1980, prólogo de Fernando Lázaro Carreter, Valladolid, 1981, pp. 35-42.

AMESTOY, Ignacio, "Sol ulcerado. Gaviotas subterráneas: burladores y burlados en el teatro de Alfonso Vallejo», Primer Acto, 251 (1993), pp. 16-17.

ASZYK, Úrsula, Entre la crisis y la vanguardia. Estudios sobre el teatro español del siglo $X X$, Varsovia, Cátedra de Estudios Ibéricos-Universidad de Varsovia, 1995.

- «Alfonso Vallejo, un autor de nuestro tiempo», introducción a Alfonso Vallejo, Crujidos. Tuatú, Madrid, Espiral / Fundamentos, 1997.

BAYÓN, Miguel, «TEC. El calvario hacia el local que no existe», Pipirijaina, 13 (1980), pp. 17-18.

- «Un tren sin destino claro. Estreno de El cero transparente, de Alfonso Vallejo, por el TEC», Diario 16, 5 de marzo de 1980, p. 22.

Berenguer, Ángel, «Bases teóricas para el estudio del teatro histórico español entre 1975 y 1998», en José Romera Castillo y Francisco Gutiérrez Carbajo (eds.), Teatro histórico (1975-1998). Textos y representaciones. Madrid, Visor, 1999, pp. 111-140.

Berenguer, Ángel y Manuel Pérez, Tendencias del teatro español durante la Transición Política (1975-1982), Historia del Teatro Español del siglo XX, IV, Madrid, Biblioteca Nueva, 1998.

BilbatúA, Miguel, «Alfonso Vallejo, un teatro de la desintegración», prólogo a Alfonso Vallejo, Monólogo para seis voces sin sonido. Infratonos. A tumba abierta, Madrid, Espiral / Fundamentos, 1979.

CENTENO, Enrique (ed.), La escena española actual (Crónica de una década: 1984-1994), Madrid, SGAE, 1996.

CENTENO, Enrique et alii, El director teatral y la puesta en escena, introducción de Juan Antonio Hormigón, Madrid, Fundación Pro-Resad, 1999.

Coco, Emilio, Teatro spagnolo contemporáneo, II, Alexandria, Edizioni dell'Orso, 2000.

DERrida, Jacques, L'écriture et la différence, París, Seuil, 1967.

DUCrot, Oswald, El decir y lo dicho, Buenos Aires, Paidós, 1984.

ECO, Umberto, Opera aperta, Milán, Bompiani, 1962.

- Lector in fabula, Barcelona, Lumen, 1981.

- Los límites de la interpretación, Barcelona, Lumen, 1992.

- Interpretación y sobreinterpretación, Cambridge, Cambridge University Press, 1995. 
FERNÁNDEZ SANTOS, Ángel, «Las huellas de la tragedia romántica», prólogo a Alfonso Vallejo, Monkeys y Gaviotas subterráneas, Madrid, Espiral / Fundamentos, 1985.

FisCher-Lichte, Erika, Semiótica del teatro, Madrid, Arco Libros, 1999.

Gómez García, Manuel, El teatro de autor en España (1991-2000), Valencia, Asociación de Autores de Teatro, 1996.

Gutiérrez CARbajo, Francisco, «La escritura teatral de Alfonso Vallejo», Teatro (Revista de Estudios Teatrales), 13-14 (junio 1998-junio 2001), pp. 29-68.

- «Contrautopía y situaciones-límite: el teatro de Alfonso Vallejo», Actas del Congreso Internacional de la Sociedad Latinoamericana de Semiótica, La Coruña, Universidad, 1999.

- «La poesía esencial de Alfonso Vallejo», introducción a Alfonso Vallejo, Eternamente a cada instante, Madrid, Huerga \& Fierro, 2000, pp. 7-15.

- «Introducción» a Alfonso Vallejo, Blanca oscuridad, Madrid, Huerga \& Fierro, 2001a, pp. 5-14.

- Teatro español contemporáneo. Alfonso Vallejo, Madrid, UNED, $2001 \mathrm{~b}$.

- Prólogo a Panic, de Alfonso Vallejo, Madrid, Editorial «La Avispa», 2001c, pp. $1-10$.

- «Elementos autobiográficos en el teatro de Alfonso Vallejo», en José Romera Castillo, con la colaboración de Francisco Gutiérrez Carbajo, Teatro y memoria en la segunda mitad del siglo XX, Madrid, Visor, 2003, pp. 95-106.

HARO TECGLEN, Eduardo, «El cero transparente. En el mundo del símbolo eterno», El País, 13 de marzo de 1980, p. 37.

KowZAN, Tadeusz, Literatura y espectáculo, Madrid, Taurus, 1992.

- «La semiología del teatro: ¿veintitrés siglos o veintidós años?», en M. C. Bobes Naves et alii, Teoría del teatro, Madrid, Arco Libros, 1997, pp. 231-252.

LOPEZ SANCHO, Lorenzo, «El cero transparente, obra de un vigoroso autor nuevo: Alfonso Vallejo», $A B C, 13$ de marzo de 1980, pp. 29-30.

Llovet, Enrique, Prólogo a Alfonso Vallejo, Cangrejos de pared. Latidos. Eclipse, Madrid, Ediciones de la Torre, 1980.

MAestro, Jesús, G. (ed.). Teatralia II. II Congreso Internacional de Teoría del Teatro. El personaje teatral, Vigo, Universidad, 1998.

MarTín, Sabas, «El teatro de Alfonso Vallejo», Cuadernos Hispanoamericanos, 416 (1985), pp. 151-157.

Mira Nouseles, Alberto, De silencios y espejos. Hacia una estética del teatro español contemporáneo, Valencia, Universidad, 1996.

Miralles, Alberto, Nuevo teatro español: una alternativa social, Madrid, Villamar, 1977. 
Oliva, César, El teatro desde 1936, Madrid, Alambra, 1989.

- «El teatro», en Francisco Rico (dir.), Historia y crítica de la literatura española, 9; Darío Villanueva et alii, Los nuevos nombres, Barcelona, Crítica, 1992, pp. 432-458.

- Teatro español del siglo XX, Madrid, Síntesis, 2002.

- La última escena (Teatro español de 1975 a nuestros días), Madrid, Cátedra, 2004.

PAVIS, Patrice, L'analyse des spectacles, Paris, Editions Nathan, 1996.

PEdraza Jiménez, Felipe y M. Rodríguez CÁCERes, Las épocas de la literatura española, Barcelona, Ariel, 1997.

PÉREZ, Manuel, La escena madrileña en la transición politica (1975-1982). Teatro (Revista de Estudios Teatrales), 3-4 (1993), Madrid, Universidad de Alcalá / Comunidad de Madrid.

RaguÉ-ArIAS, María José, El teatro de fin de milenio en España (de 1975 hasta hoy), Barcelona, Ariel, 1996.

RICOEUR, Paul, Tiempo y narración, I y II, Madrid, Cristiandad, 1987.

SANTA CRuZ, Dolores, «Alfonso Vallejo: teatro para hambrientos», El Público, 9 (1984), pp. 26-27.

STANISLAVSKI, Constantin, Un actor se prepara, México D. F., Editorial Constancia, 1953.

TORO, Fernando del y W. FLoECK (eds.), Teatro español contemporáneo. Autores $y$ tendencias, Kassel, Reichenberger, 1995.

VAlleJo, Alfonso, El cero transparente. Áido sulfuirico. El desguace, Madrid, Espiral / Fundamentos, 1978.

- A tumba abierta. Monólogo para seis voces sin sonido. Infratonos, Madrid, Espiral / Fundamentos, 1979.

- Cangrejos de pared Latidos. Eclipse, Madrid, Ediciones de la Torre, 1980.

- Orquideas y panteras, Madrid, Editorial Presión, 1985a.

- Monkeys. Gaviotas subterráneas, Madrid, Espiral/Fundamentos, 1985b.

- Hölderlin, Madrid, Primer Acto, 205 (1985c), pp. 80-102.

- Fly-By. Sol ulcerado, Madrid, La Avispa, 1986a.

- Espacio interior. Week-end, Madrid, Espiral / Fundamentos, 1986b.

- La espada del circulo, Murcia, Universidad, 1989.

- Crujidos. Tuatú, Madrid, Espiral / Fundamentos, 1997.

- Kora, Madrid, Visor, 1998a.

- Jindama, Salobreña (Granada), Alhulia, 1998 b.

- Ébola-Nerón, Murcia, Escuela Superior de Arte Dramático, 1999.

- Eternamente a cada instante, Madrid, Huerga \& Fierro, 2000 a.

- «La grandeza del actor», Revista de la Unión de Actores, 58 (2000b), pp. 27-29. 
- Blanca oscuridad, Madrid, Huerga \& Fierro, 2001a.

- Panic, Madrid, La Avispa, 2001 b.

VILCHES DE FRUTOS, María Francisca, «Introducción» a Alfonso Vallejo, Ébola-Nerón, Murcia, Escuela Superior de Arte Dramático, 1999.

VILCHES de FruTOS, María Francisca y Luiciano GARCía LORENZO, «La temporada teatral española», en Anejos de Segismundo, Madrid, CSIC, 1983.

WellwarTH, George, Spanish Underground Drama (Teatro español underground), Madrid, Villalar, 1978. 